\title{
INTERCULTURAL COMMUNICATION AND SUSTAINABLE PEACE IN THE BALKANS
}

\author{
Aleksandar Pavleski, PhD \\ Faculty of Philosophy \\ E-mail: pavleski@fzf.ukim.edu.mk
}

\section{Abstract:}

The paper analyzes the complexities of the nexus between intercultural communication and sustainable peace agenda in the Balkans. In the first section, the article elaborates the theoretical aspects of this nexus, while the main focus of the second section is on the development and improvement of the effective communication and cooperation as tools for a sustainable peace in the Balkans. The article analyzes the Balkan intercultural communication development in past two decades as well as its barriers and challenges. On other hand, it elaborates the sustainable peace approach through the prism of initiatives based upon long-term developmental, political, economic, societal and social objectives. The basic premise is that an improved and effective intercultural communication will provide for easier achieving of these objectives.

Key words: Intercultural communication, sustainable peace, cooperation, the Balkans

\section{Introduction}

Intercultural tolerance may be the most difficult trial for any society, especially in the modern times. To accept issue we are unfamiliar with, something which deviates from our tradition, customs and habits, is indeed a challenge. If there is no tolerance, there will be no coexistence. In order to be able to understand devotees of other cultures, it is necessary to understand both their and one's own worldviews, especially if the main goal is living together.

Generally, cultural diversity creates both obstacles and opportunities for peaceful coexistence. Therefore, communication between people as well as between the states with different national cultures, or so-called intercultural communication, is the main instrument that enables their mutual connection, understanding, respect and functioning in the every-day life. Exactly these are the basic aspects of peacebuilding and sustainable peace process among peoples and the states. Intercultural communication shapes and is shaped by the beliefs we hold about the nature 


\section{Security}

and the prospect for peace in general. For instance, the skills of effective and ethical intercultural communication contribute substantially to peaceful outcomes across a variety of intercultural contexts, where divisive conflict and numbing indifference often prevail. It is especially important for regions (such as the Balkans) inhabited by people with different cultures. Moreover, having in mind that various forms of political, societal and economic instability and conflicts in the Balkans, especially in so-called Western Balkans, have made communication and cooperation impossible at the end of the 20th century. As a response to those circumstances various forms of regional initiatives were promoted in the past two decades in order to foster conciliation and rapprochement. Therefore, the paper analyzes the characteristics of these regional initiatives and their influence and relations with intercultural communication as well.

\section{Theorizing about Intercultural Communication}

Despite its increasingly common use in a range of diverse contexts, there is a lack of common understanding about the definition of intercultural communication. Hence, intercultural communication is usually conceptualized as communication between people with different national cultures, and many scholars limit it to face-to-face communication. Consequently, it could be seen as a type of intergroup communication which includes numerous and various types of communication that may not be included in the category of intercultural communication, such as: communication between members of different social classes, interracial/interethnic communication, etc.

Theoretically, there is no a universal definition on intercultural communication. Depending of the theoretical focus, one may identify a few theoretical approaches. These are generally based on objectivist and subjectivist view of intercultural communication. For instance, objectivists see a real world external to individuals, look for regularities in behavior and see communication as determined by situations and environments. Subjectivists, in contrast, contend that there is no real world external to individuals, try to understand individual communicators' perspectives, and view communication as a function of free will. Still, it should be noted that extreme objectivist or subjectivist perspectives are not defensible. They are both necessary for understanding intercultural communication.

Kincaid, a cultural convergence representative, defines communication as a process in which two or more individuals or groups share information in order to reach "a mutual understanding of each other and the world in which they live" (1988: 32). He summarizes the theory in several hypotheses, such as: 1 ) in relatively closed social system in which communication among members is unrestricted, the system as a whole will tend to converge over time toward a state of greater cultural uniformity; 2) the system will tend to diverge toward diversity when communication is restricted. On the other hand, Gudykunst (1993:33) assumes that individuals' communication is influenced by their cultures and group memberships, but they also can choose how they communicate when they are mindful. Additionally, he argues that there are basic causes of effective communication. Therefore, he contends that anxiety and uncertainty management 
are the basic causes of effective communication and the effect of other variables (e.g. ability to empathize, attraction to strangers) on effective communication is mediated through anxiety and uncertainty management. The extent to which individuals are mindful of their behavior moderates the influence of their anxiety and uncertainty management on their communication effectiveness. Actually, this is the essential aspect of anxiety/uncertainty management theory.

According to Ellsworth (1983) all communication involves some degree of cultural variability. He suggests that explaining intercultural communication needs to start from interpersonal communication and cultural factors need to be incorporated as well. Starting from this point of view, he suggests several propositions that functionally adapting communication. Actually, first of all nonfunctional adaptive communication leads to invocation of cultural differences and slowing task completion. In other hand, using persuasive strategies leads to adapting communication, as well as when the situation favors one communicator or when one communicator has more power, than the other communicator has the burden to adapt. The more adaptive behavior in which communicators engage, the more their cultural beliefs will change.

Orbe (1998) tries to explain intercultural communication through the prism of cocultural theory. He speaks about co-cultural communication which refers to interactions among underrepresented and dominant group members. He points out that co-cultural group members generally have one of three goals for their interactions with dominant group members: 1) assimilation (e.g. to become part of the mainstream culture), 2) accommodation (e.g. try to get the dominant group members to accept co-cultural group members), or 3) separation (e.g. rejecting the possibility of common bonds with dominant group members). Other factors that influence co-cultural group communication are: field of experience (e.g., past experiences); abilities (e.g., individuals' abilities to enact different practices); the situational context (e.g., where are they communicating with dominant group members); communication approach (i.e., being aggressive, assertive, or nonassertive).

Cupach and Imahori (1993: 113) have developed an identity management theory which is based in interpersonal communication competence. They view identity as providing "an interpretative frame for experience". Identities provide expectations for behavior and motivate individuals' behavior. Individuals have multiple identities, but Cupach and Imahori points out to cultural and relation identities as central to identity management. An interpersonal communication competence in their theoretical approach includes the ability of an individual for successfully negotiation and interaction in different environment identities. Moreover, they argue that because individuals often don't know much about others cultures, an intercultural dimension is being perceived by using stereotypes. Stereotyping, however, is not acceptable because it is based on externally imposed identities.

\section{Intercultural Communication Competence}

Intercultural communication competence is the ability to communicate effectively and appropriately in various cultural contexts. Actually, intercultural communication competence 
involves knowledge, motivation and skills to interact effectively and appropriately with members of different cultures. The knowledge component includes what the people know about the culture that informs and guides their choices of what to think, say, and do in a particular situation. Listening to people who are different from us is a key component of developing self-knowledge. This may be uncomfortable, because we may realize that people think of our identities differently than we thought. Ignorance of a culture norms, rules, symbols and expressions can lead to missteps and misunderstandings. Therefore, a knowledgeable communicator needs information about the people, the communication rules, the context and the normative expectations governing the interaction with the member of other culture. Without this information the communicator will invariably make misattributions, choose incorrect communication strategies, and violate rules or etiquette as well. Furthermore, the unknowing communicator may not be able to correctly ascribe the reasons for the errors or be able to remedy them.

Motivation refers to the set of feelings, intentions, needs and drives associated with the anticipation of or actual engagement in intercultural communication. Factors such as anxiety, perceived social distance, attraction, ethnocentrism and prejudice can influence an individual's decision to communicate with another. Actually, if fears, dislikes and anxieties predominate people affect toward the other, then they will have negative motivation and they will be likely to avoid the interaction, even they have the requisite knowledge and skills to perform. In other hand, if people confidence, interests, likes and good intentions predominate the affect toward the other, they will have positive motivation and will seek out and engage in interaction with other. Moreover, members of dominant groups are often less motivated, intrinsically and extrinsically, toward intercultural communication than members of non-dominant groups, because they don't see the incentives for doing so. Having more power in communication encounters can create an unbalanced situation where the individual from the non-dominant group is expected to exhibit competence, or the ability to adapt to the communication behaviors and attitudes of the other. However, motivation alone cannot create intercultural communication competence.

Actually, knowledge and motivation are not enough for effective intercultural communication. Even the most informed and well-intentioned person needs certain skills to achieve high levels of intercultural communication competence. Some of the skills that are very important in developing intercultural communication competence, are: the ability to empathize, accumulate cultural information, listen and resolve conflict. Skills refer to the actual performance of the behaviors felt to be affective and appropriate in the communication context. For example, if a person accidentally produces a behavior that is perceived as competent, that wouldn't be adequate, because the person may not be able to replicate the same behavior with the same effect. No sensible discussion of communication competence is possible without considering these three components. These three components are equally applicative for official communication between different countries as well.

Regarding to the global values of intercultural interactions, this paper argues that peace is the fundamental human value. The use of peace applies not only to relationships among countries, but to the right of all people to live at peace with themselves and their surroundings. From 
this fundamental value, Kale (1997: 450) developed four ethical principles to guide intercultural interactions:

- Ethical communicators address people of other cultures with the same respect that they would like to receive themselves. Intercultural communicators should not demean or belittle the cultural identity of others through verbal or nonverbal communication.

- Ethical communicators seek to describe the world as they perceive it as accurately as possible. What is perceived to be the truth may vary from one culture to another-truth is socially constructed. This principle means that ethical communicators do not deliberately mislead or deceive.

- Ethical communicators encourage people of other cultures to express themselves in their uniqueness. This principle respects the right of people to expression regardless of how popular or unpopular their ideas may be.

- Ethical communicators strive for identification with people of other cultures. Intercultural communicators should emphasize the commonalities of cultural beliefs and values rather than their differences.

These ethical principles emphasize the complexity of the intercultural communication process. Therefore, developing ethical principles for guiding intercultural interactions is a difficult task and these principles might be more acceptable in some cultures than in others. Ethical communication is fundamental to responsible thinking, decision making and the development relationships and communities within and across contexts and cultures. Moreover, ethical communication enhances human worth and dignity by fostering truthfulness, fairness, responsibility, personal integrity and respect for self and others. Therefore, people and states as well, should fostering and enhancing intercultural ethical communication.

\section{Sustainable Peace Approach}

In peacebuilding literature, there are two basic categories of peace: positive peace and negative peace. Negative peace simply means that there is no overt expression of large-scale physical violence (Galtung, 1969). Negative peace relies on the threat of or potential for violence; expressed in western societies at the hands of the state in the police, national guards, and criminal justice system. Whereas positive peace refers to the conditions chosen by people, in relationship with one another, at any level in society from local to national, who are actively working together to generate conditions of peacefulness. It is more than just the absence of violence but the intentional creation of conditions of peace and well-being for the whole group.

The objective for positive peace is to resolve deeply rooted causes of conflict so that conditions for violent conflict are removed or resolved (Sandole, 2003). Actually the establishment of a strong, long-term, durable, positive peace requires the cooperation of number of stakeholders attending to a wide range of variables on a number of levels, depending on how complex or entrenched the conflict situation is or might become. 


\section{Security}

Sustainable peace is where the values of positive peace are featured which necessitate finding different solutions to conflict than ones which are found in structures of pacification, or negative peace. Sustainable, positive peace does not use violence in any form - whether structural, cultural, economic, legal or physical - to resolve conflict. Expressions of violence, although they may halt a particular instance of conflict and restore the semblance of order, affect the ongoing quality of a relationship between different parties.

If no violence is used in the handling of a particular instance of conflict, the quality of the relationship between the parties may in fact improve through processes of conflict transformation where both parties learn to view one another and the contested issue or item in a different light. In this transformational space, new solutions can be devised between the parties which have a greater likelihood of benefitting all concerned. Actually, non-violent conflict transformation is a durable solution that contributes to sustainable peace.

In general, it could be noted that the most important steps towards a sustainable peace are those which foster and strengthen local and national capacity for dealing with the past, engaging with the present, and shaping the future in ways which don't exclude, oppress, or divide. Therefore, creating the conditions for sustainable peace means deconstructing structures, situations and relationships that cause conflict while building structures, situations and relationships that support peace.

Sustainable peace frames the development of constructive personal, group, and political relationships across ethnic, religious, class, national, and racial boundaries. It aims to resolve injustice in nonviolent ways and to transform the structural conditions that generate deadly conflict. Therefore, sustainable peace becomes strategic when it works over the long run and at all levels of society or region to establish and sustain relationships among people locally, regionally and globally. Sustainable peace connects people and groups "on the ground" (community and religious groups, grassroots organizations, etc.) with policymakers and powerbrokers (governments, the United Nations, corporations, banks, etc.). It aims not only to resolve conflicts, but to build societies, institutions, policies, and relationships that are more able to sustain peace and justice. Therefore, sustainable peace address issues of human rights, economic prosperity and environmental sustainability as well as violence.

\section{Nexus between Intercultural Communication and Sustainable Peace}

Starting from the hypothesis that intercultural communication can build more productive and peaceful communities, this paper argues that any communication between people as well as among the countries of different cultures is better than no communication between them. As mentioned above, sustainable peace approach is multilayered and wide in scope, encompassing work at all levels of society, from international and regional partnerships to personal friendships.

Interactions with people of other cultures offer opportunities along to road to more peaceful communities. Actually intercultural communication competence gives the needed tools for building bridges over the cultural divides. According to Allport (1954), interracial contact does 
not automatically or always reduce prejudice, but will under four conditions: 1) equal status among group members; 2) group members working toward a common goal; 3) cooperative interaction among group members; and 4) clear institutional forms of support for intergroup contact. Although his work concentrated initially on race relations, intergroup contact theory has widened over the years to include prejudice based on ethnicity, religion, disability, sexuality and even professional associations. It is no doubt that in all of these sphere, his conditions are identified as necessary instead to enhance the positive effects of contact on prejudice.

Actually, one way that contact reduces prejudice is by increasing knowledge about other cultural groups. The more people interact with persons from of other cultures, they will more learn about them as representatives of various cultural groups. This knowledge includes ways in which other cultures are similar to and different from people own culture, making it possible to find a common ground while also appreciating cultural differences. Another way that contact reduces prejudice is by facilitating empathy and perspective taking. Intergroup contact, especially when it fosters close personal relationships, makes easier taking and understanding perspective of outgroup members, share their emotional experiences and empathize with their concerns, thereby improving intergroup attitudes.

It should also be noted that our contact with people from other cultures equips us with greater knowledge, empathy and perspective taking and makes us fell less threatened and anxious about our intercultural communication. $\mathrm{On}$ other hand, as mentioned above, sustainable peace could be perceived as an effort for constructing new living conditions. In that context, peacebuilding includes taking concrete measures and cooperative projects that link two or more countries with the final goal of achieving their economic and social development as well as increasing mutual trust as the basis peace component. Therefore, intercultural communication is the main instrument that provides connection between different people and countries.

\section{Intercultural Communication, Cooperation and Sustainable Peace in the Balkans}

The Balkan Peninsula is a place where different cultures and religions meet: Christianity, Islam and Judaism. Interestingly, despite the fact that all these cultures and religions are essentially similar to one another, being derived from a common ancient basis in Judaism and all preaching peace as an ideal, the Balkans have always been considered among the most conflicting regions in the world.

Various forms of political, societal and economic instability and conflicts in the Balkans, have made communication and cooperation impossible since the end of the 20th century. As a response to those circumstances various forms of regional initiatives were promoted in the past two decades in order to foster conciliation and rapprochement. From this point of view, the regional communication and cooperation in the Balkans could be analyzed from two points of view.

First, in the last two decades, the regional cooperation and communication as well, has been mainly initiated by the International community. Actually, in spite of the numerous problems that are part of the historical "baggage" of the region, the promise of EU accession, has had a 


\section{Security}

transformative effect and has stimulated the beginning of the regional recovery and stabilization. Hence a major factor affecting all communications in the Balkans region is the EU integration process, which is currently perceived as the future settlement in a space where administrative and political divisions are no more significant neither have substantial influence, above all communications and exchanges give a totally different meaning to all differences including the cultural aspect. This means that intercultural dialogue in the Balkans is the logical consequence of the reflection about European integration. Actually, EU is perceived as a leading promoter of intercultural dialogue, by involving governments and civil society actors as well as by ensuring that human rights are accorded a central place, in the building of a new and inclusive Balkan region.

Second, the objective of regional cooperation has been aimed at establishing mutual trust, as well as at rebuilding relations in previous un-security region. As mentioned above, a mutual trust is exactly one of the main goal of intercultural communication. Therefore, it can be perceived as an instrument for reducing or eliminating the possibilities of violence resurgence as well as an instrument for producing development and prosperity conditions in the region. Actually, this aspect draws the link among communication and sustainable peace in the Balkans. The impact of communication and sustainable peace can be analyzed through the prism of two components: 1) the number of cooperation initiatives and states participating in them, and 2) the realization level of initiative objectives. The first one illustrates how Balkans countries is being prepared for communication and cooperation, while the second one, illustrates their real commitment about communication and cooperation. Related to this, it can be pointed out that almost all initiatives for regional cooperation have been signed and accepted by all countries in the Balkans. This is significant because it expresses a clear intention and readiness of countries for common action in the context of peaceful resolution of outstanding issues as well as in the context of ensuring a peaceful, stable and prosperous region.

Regarding to the second component - the objectives of regional cooperation initiatives - it should be noted that all previous initiatives have been aimed at promoting regional communication and cooperation as a factor for regional peace, security, stability and prosperity. From today's perspective, it is undoubted that these initiatives have had a significant contribution in the strengthening of mutual trust and thus in the strengthening of regional peace and stability. Actually, all of them have initiated a new, positive social behavior in the region.

The positive impact in the political sphere is based on renewed and enhanced political dialogue as well as on the strengthening of mutual trust, mutual understanding and convergence among the Balkan countries. Hence, in terms of sustainable peace, declarations of good neighborly relations, cooperation, peace and stability adopted by separate initiatives, have crucial importance. Such are: Sofia Declaration on Good-Neighbourly Relations, Stability, Security and Cooperation in the Balkans (1996); the Charter of Good Neighbourly Relations in South-Eastern Europe (2000); the Joint Declaration on Comprehensive Cooperation in South-Eastern Europe (2000); Declaration on Intercultural dialogue and conflict prevention (2003). Moreover, communication 
and cooperation in the political sphere based on respecting the established principles by the UN Charter, the Helsinki Document and the Paris Charter for a New Europe, is also an important component that positively affects peacebuilding and sustainable peace in the Balkans.

On other hand, intercultural communication also takes place through the educations, building of roads, opening of markets, and the creation of physical spaces etc. Therefore, in the economic sphere, communication and cooperation in Balkans has been based on economic regeneration as well as on the creation of conditions for its prosperity and development. Actually, the activities in the economic sphere were directly aimed at promoting economic growth, attracting investment and establishing acceptable welfare level in the region. Obviously, these goals could be related to the objectives of sustainable peace. There is no doubt that economic growth and maintaining an acceptable welfare level will positively affect the regional peace and stability.

There is no doubt that this interconnection trend among the Balkans countries should continue in the future, moreover because of:

- objective depending and direction of neighbors to each other, especially considering the relative narrowness of national markets;

- a need for better use of one or more shared resources which is in correlation with reducing of the economic incoherence of the region;

- a need for a common response to the contemporary security risks and threats;

- existence of positive examples related to the regionalism effects in many European regions, such as: Nordic, Benelux, Baltic regions.

Generally, it could be noted that political initiatives for regional cooperation have main influence in developing and fostering intercultural communication in the Balkans in past two decades. These initiatives have promoted strengthening of mutual trust and mutual understanding among the Balkan countries. Still this is so-called top-down approach. Therefore, the Balkan countries must stay more focused on the civil society initiatives in the next period. The representatives of academic, business, sport and cultural sphere, should have a crucial role in intercultural communication development and enhancement. Mutual learning and mutual trust are of vital importance to Balkans future. Therefore, the need for education promoting intercultural dialogue, cultural diversity and human dignity is crucial.

\section{Conclusion}

Intercultural communication involves the exchange of meaningful messages between individuals of different cultural groups. Having in mind the new security risks and threats which usually involves and cultural aspects, especially in multicultural regions such is Balkans, there is no dilemma that intercultural dialogue could has a vital role in securing global and regional peace as well. Actually, this dialogue can defuse tensions and keep situations from escalating. It can also promote reconciliation in the aftermath of conflict. Almost all of major theories of intercultural communication emphasize its power to use communication to bring together the different. 


\section{Security}

Intercultural communication could be perceived as a particular process that occurs between a groups of people and state as well, which are talking together, communicating to understand each other and developing mutual respect on which community can be built, sustained or repaired.

The article argues that intercultural communication has had a positive impact on peace, stability and prosperity in the Balkans in the past two decades. More precisely, an intensive communication as well as cooperation in various fields has produced a particular political energy that is aimed more towards mutual respect and integration of the region. Still, the intercultural communications in the Balkans has dominant (external) political impact. Therefore, it couldn't be talk about authentic intercultural dialogue in the Balkans today. The Balkan countries should be more focused on civil society dimension of intercultural communication in the next period. They also should continue to combine their efforts on building and promoting a new identity and image of a region that, is (slowly) on its way to becoming an area of stability and peace.

\section{References}

1. Allport, G. (1954) The nature of prejudice. Cambridge: Addison-Wesley Pub.

2. Cupach, W.R. Imahori, T. (1993) Identity Management Theory - Communication competence in intercultural episodes and relationships. Newbury Park, CA: Sage.

3. Ellsworth, K. (1983) The Grand Sweep (365 Days from Genesis Through Revelation): A Bible Study for Individuals and Groups. Nashville: Abingdon Press.

4. Ellsworth, K. (2011) Faith from the Back Side: A Different Take On What It Means To Believe. Nashville: Abingdon Press.

5. Galtung, J. (1969) "Violence, Peace and Peace Research", Journal of Peace Research, 6(3), 167-191.

6. Gudykynst, W.B. (2003) Cross-cultural and Intercultural communication. London: SAGE Publications.

7. Kale, D.W. (1997) "Peace as an ethic for intercultural communication". In: L.A. Samovar \& R.E.Porter (eds.), Intercultural Communication: A reader, Belmont, CA: Wadsworth.

8. Kincaid, L.D.(1988) Communication theory: Eastern and Western Perspective. Academic Press.

9. Orbe, M.P. (1998) Interracial Communication: Theory into practice. London: SAGE Publications.

10. Sandole, J.D. (2003) Peace and Security in the Postmodern World. London: Routledge Studies in Peace and Conflict Resolution. 